\title{
Osseous Sarcoid
}

EVELYN W.Y. KWOK, MD; ELAINE A. YACYSHYN, MD, FRCPC, Faculty of Medicine, University of Alberta, Edmonton, Alberta, Canada. Address correspondence to Dr. E. Yacyshyn, Department of Rheumatology, 562 HMRC, University of Alberta, Edmonton, Alberta T6G2S2, Canada. E-mail: eyacyshyn@ualberta.ca. J Rheumatol 2015;42:723-4; doi:10.3899/jrheum.141025

Sarcoidosis is a heterogeneous systemic inflammatory disease characterized by the non-caseating granulomatous inflammation of tissues. Pulmonary involvement (90\%) and cutaneous manifestations $(25 \%)$ are most common ${ }^{1}$. Osseous involvement has been quoted at $3 \%$ to $13 \%{ }^{2}$.

A 69-year-old man was diagnosed in 1969 with pulmonary sarcoidosis through a chest radiograph and neck lymph node biopsy. This was managed with oral corticosteroids and he had been in clinical remission for the last 12 years, not requiring ongoing treatment.

$\mathrm{He}$ was referred to a rheumatologist with destructive osseous lesions of his hands and feet. He described having a minor injury to his left great toe 35 years ago, which progressed to infection and amputation. His left third and fourth fingers were surgically amputated distal to the metacarpophalangeal joints following similar progressions. Physical examination revealed right fourth and fifth, and left second digit shortening deformities and dysmorphic nails (Figure 1). A radiograph of the hands (Figure 2) revealed amputated left third and fourth fingers at the midshaft of the proximal phalanges with gracile changes to the stump of the left third proximal phalanx. Destruction to the proximal and distal phalanx of the right little finger was present. Cyst-like lesions were present within the proximal phalanges of the left index and middle fingers, right index finger, and left distal radius and triquetrum in keeping with osseous sarcoid.

Osseous sarcoid typically affects small bones, most commonly the middle and distal phalanges ${ }^{3,4}$. Radiographic findings include osteosclerosis, osteolysis, cystic changes, and trabecular latticework or honeycomb pattern. Overlying soft tissue swelling and extensor tendon rupture may occur. Treatment involves systemic corticosteroids, antimalarials, and surgery 4 .

\section{REFERENCES}

1. Ugwonali OF, Parisien M, Nickerson KG, Scully B, Ristic S, Strauch RJ. Osseous sarcoidosis of the hand: pathologic analysis and review of the literature. J Hand Surg Am 2005;30:854-8.

2. Wilcox A, Bharadwaj P, Sharma OP. Bone sarcoidosis. Curr Opin Rheumatol 2000;12:321-30.

3. Duckworth AD, Hill AT, Beggs I, Patton JT, Salter DM, Porter DE. Sarcoidosis presenting as a proximal phalangeal bony swelling-a case and review of the literature. Hand 2010;5:90-4.

4. Shorr AF, Murphy FT, Kelly WF, Kaplan KJ, Gilliland WR, Shapeero LG. Osseous sarcoidosis clinical, radiographic, and therapeutic observations. J Clin Rheumatol 1998;4:186-92.

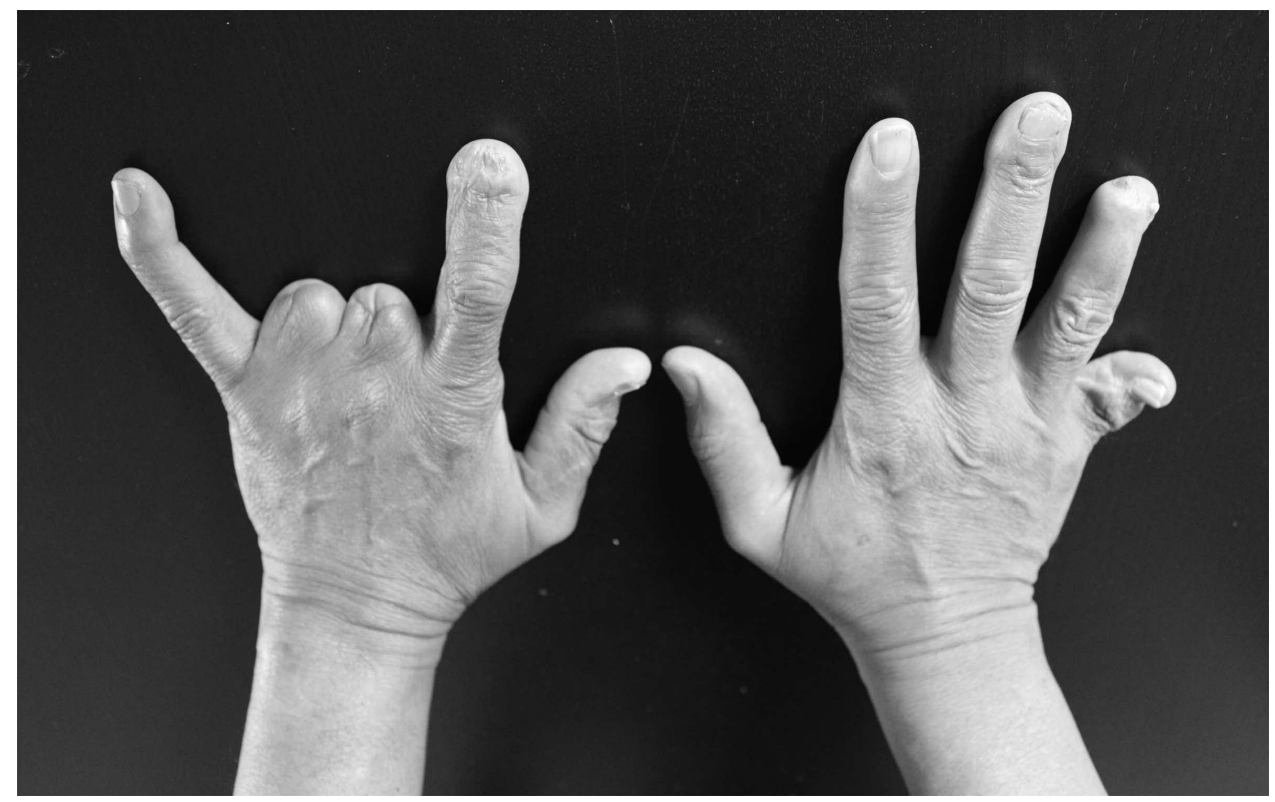

Figure 1. Osseous sarcoidosis of the hands showing right fourth and fifth, and left second digital shortening, as well as nail disruption. 


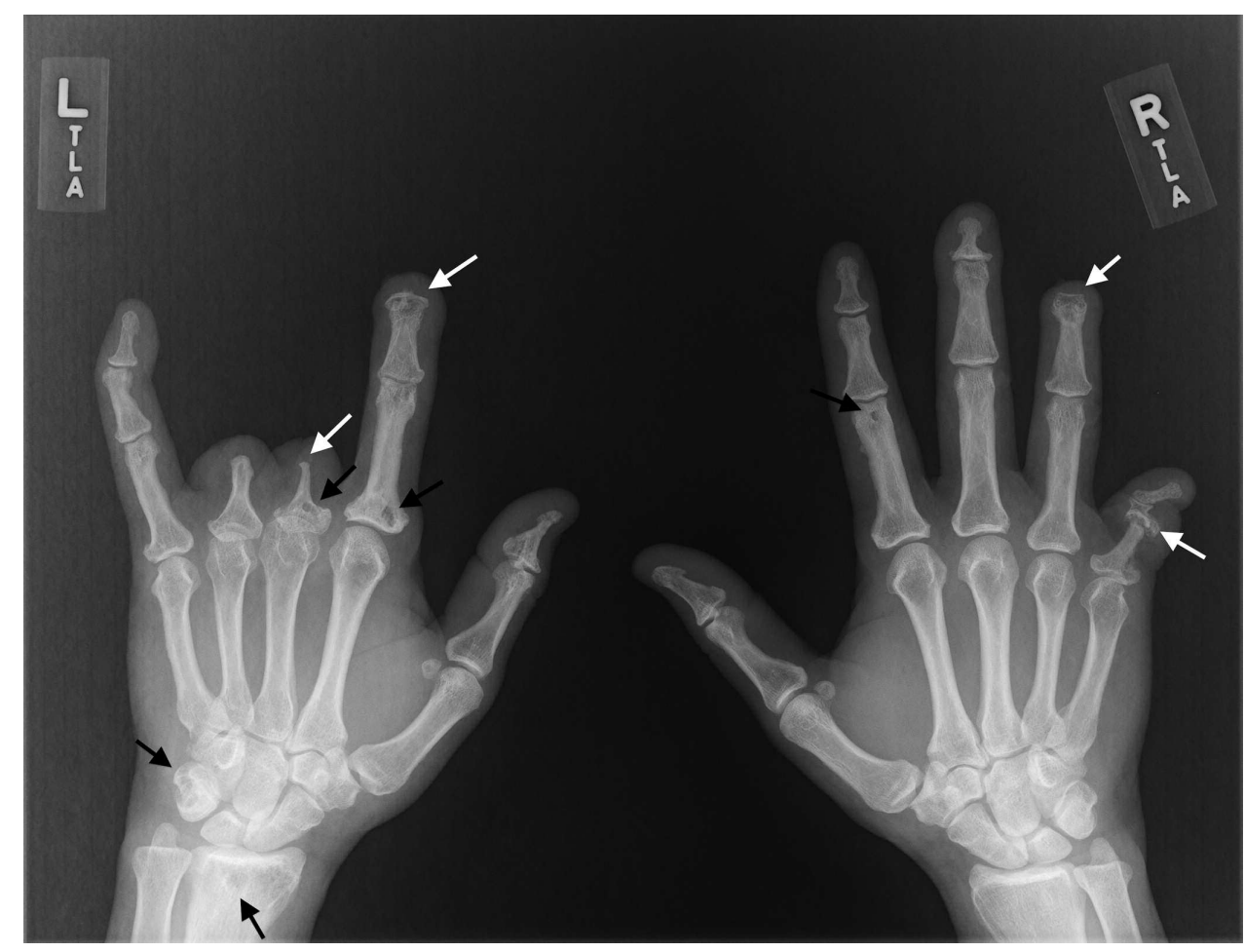

Figure 2. Radiograph of osseous sarcoidosis of the hands exhibiting osteolysis (white arrows), cystic changes (black arrows), and severe right fifth proximal interphalangeal joint disruption. 